Int. J. Electrochem. Sci., 11 (2016) $6808-6818$

International Journal of

ELECTROCHEMICAL

SCIENCE

www.electrochemsci.org

\title{
Effect of Different Conductive Additives on the Electrochemical Properties of Mesoporous $\mathrm{MnO}_{2}$ Nanotubes
}

\author{
Xiao Wang, Xiaoli Liu, Ke Chen ${ }^{*}$ \\ College of Materials Science and Engineering, Chongqing University, Chongqing 400044, PR China \\ *E-mail: chenke1_cqu@163.com
}

doi: $10.20964 / 2016.08 .26$

Received: 30 April 2016 / Accepted: 5 June 2016 / Published: 7 July 2016

\begin{abstract}
$\mathrm{MnO}_{2}$ as an environmental benignity material has been of great interest for supercapacitors due to its unique properties leading to improved performances. Herein we describe the effects of different conductive agent to improve the electrochemical properties of $\mathrm{MnO}_{2}$ nanotubes. Three typical conductive additives: carbon black, carbon nanotubes, and graphene are chosen to mix with $\mathrm{MnO}_{2}$ nanotubes in the working electrodes. The specific conductivities of $\mathrm{MnO}_{2} @$ carbon black particles electrode, $\mathrm{MnO}_{2} @$ carbon nanotubes electrode, and $\mathrm{MnO}_{2} @$ graphene electrode at the current density 1 $\mathrm{A} \mathrm{g}^{-1}$ are $244.8 \mathrm{~F} \mathrm{~g}^{-1}, 190.2 \mathrm{~F} \mathrm{~g}^{-1}$, and 114.1 $\mathrm{F} \mathrm{g}^{-1}$ respectively. Furthermore, $\mathrm{MnO}_{2} @$ carbon nanotubes electrode possesses an electrochemical capacitance as high as $297.5 \mathrm{~F} \mathrm{~g}^{-1}$ at the current density $0.5 \mathrm{~A} \mathrm{~g}^{-}$ 1 , which can be put down to these soft thin nanotubes can be intertwined with each other to form a powerful network to provide conduction. In principle, the high specific capacitance and stable structure of the $\mathrm{MnO}_{2} @$ carbon nanotubes electrode ensures its potential for the applications in supercapacitors and other microelectronics.
\end{abstract}

Keywords: graphene; carbon blacks; carbon nanotubes; manganese dioxide nanotubes; supercapacitors

\section{FULLTEXT}

(C) 2016 The Authors. Published by ESG (www.electrochemsci.org). This article is an open access article distributed under the terms and conditions of the Creative Commons Attribution license (http://creativecommons.org/licenses/by/4.0/). 